J. Appl. Numer. Optim. 1 (2019), No. 1, pp. 25-38

Available online at http://jano.biemdas.com

https://doi.org/10.23952/jano.1.2019.1.03

\title{
VISCOSITY APPROXIMATION METHODS FOR FIXED POINT PROBLEMS IN HILBERT SPACES ENDOWED WITH GRAPHS
}

\author{
W. CHOLAMJIAK ${ }^{1}$, S. SUANTAI ${ }^{2}$, R. SUPARATULATORN ${ }^{2}$, S. KESORNPROM $^{1}$, P. CHOLAMJIAK ${ }^{1, *}$ \\ ${ }^{1}$ School of Science, University of Phayao, Phayao 56000, Thailand \\ ${ }^{2}$ Department of Mathematics, Faculty of Science, Chiang Mai University, Chiang Mai 50200, Thailand
}

\begin{abstract}
In this paper, we investigate the existence of fixed points for $G$-nonexpansive mappings and prove strong convergence theorems of a sequence generated by two different viscosity approximation methods for finding fixed points of these mappings in a Hilbert space with a directed graph. We also give examples and numerical results to support our main convergence theorem. Keywords. Bregman best proximity point; Fixed point; Bregman proximal pointwise contraction; Cyclic mapping; Property BUC.
\end{abstract}

2010 Mathematics Subject Classification. 47H09, 65K15.

\section{INTRODUCTION}

Let $C$ be a nonempty, closed and convex subset of a normed space $X$. A mapping $T: C \rightarrow C$ is said to be

1. contraction if there exists $\alpha \in(0,1)$ such that $\|T x-T y\| \leq \alpha\|x-y\|$ for all $x, y \in C$;

2. nonexpansive if $\|T x-T y\| \leq\|x-y\|$ for all $x, y \in C$.

The fixed-point set of $T$ is denoted by $F(T)$, that is, $F(T)=\{x \in C: x=T x\}$.

In 1922, Banach [2] established the famous fixed point result of a contractive mapping in complete metric spaces, known as the Banach's contraction principle, which is an important tool for solving the existence problem of nonlinear equations. Since then, many generalizations of this fixed point theorem have been investigated in several directions.

In 1967, Browder [3] employed the Banach's contraction principle to prove the existence of fixed points of nonexpansive mappings in Banach spaces. For related existence results on fixed points of nonexpansive mappings, we refer to $[6,8]$ and the references therein.

For nonexpansive mappings with fixed points, Mann iterative method is a ordinary tool to study them. However, only weak convergence is guaranteed in infinite dimensional spaces. Let $H$ be a Hilbert space and let $T: C \rightarrow C$ be a nonexpansive mapping. In 1967, Halpern [5] introduced the following classical iteration for fixed points of mapping $T$ in space $H$ :

$$
x_{n+1}=\alpha_{n} u+\left(1-\alpha_{n}\right) T x_{n}, \quad n \geq 0,
$$

${ }^{*}$ Corresponding author.

E-mail addresses: c-wchp007@hotmail.com (W. Cholamjiak), suthep.s@cmu.ac.th (S. Suantai), raweerote.s@gmail.com (R. Suparatulatorn), suparat.ke@gmail.com (S. Kesornprom), prasitch2008@yahoo.com (P. Cholamjiak)

Received August 14, 2018; Accepted January 26, 2019.

(C)2019 Journal of Applied and Numerical Optimization 
where $\alpha_{n} \in(0,1)$ and $u \in C$.

In 1992, Wittmann [15] studied the Halpern iteration and proved that the sequence $\left\{x_{n}\right\}$ generated in above iteration converges strongly to a fixed point of nonexpansive mapping $T$ in Hilbert space $H$ if $\left\{\alpha_{n}\right\}$ satisfies the following conditions:

$$
C 1: \lim _{n \rightarrow \infty} \alpha_{n}=0 ; C 2: \sum_{n=0}^{\infty} \alpha_{n}=\infty ; C 3: \sum_{n=0}^{\infty}\left|\alpha_{n+1}-\alpha_{n}\right|<\infty .
$$

In 2000, Moudafi [10] introduced the following viscosity approximation method: $x_{0} \in C$ and

$$
x_{n+1}=\alpha_{n} f\left(x_{n}\right)+\left(1-\alpha_{n}\right) T x_{n}, \quad n \geq 0,
$$

where $\alpha_{n} \in(0,1), f: C \rightarrow C$ is a contraction and $T: C \rightarrow C$ is a noenxpasnvie mapping. He proved that the sequence $\left\{x_{n}\right\}$ generated in (1.1) converges strongly to a fixed point of $T$ and the fixed point also solves some variational inequality if $\left\{\alpha_{n}\right\}$ satisfies $C 1, C 2$ and $C 3$. This result plays a fundamental role in recent research on fixed-point iterations.

In 2006, Xu and Marino [16] extended Moudafi's results [10] via the following general iteration: $x_{0} \in H$ and

$$
x_{n+1}=\left(I-\alpha_{n} A\right) T x_{n}+\alpha_{n} \gamma f\left(x_{n}\right), n \geq 0,
$$

where $\left\{\alpha_{n}\right\} \subset(0,1), \gamma$ is some real number, $A$ is bounded linear operator $H$ and $T$ is a nonexpansive mapping on $H$. If $\left\{\alpha_{n}\right\}$ satisfies $C 1, C 2$ and $C 3$, they proved that the sequence $\left\{x_{n}\right\}$ converges strongly to $\hat{x}$, where $\hat{x}$ is also the unique solution of the following variational inequality

$$
\langle(I-f) \widehat{x}, x-\widehat{x}\rangle \geq 0, \quad \forall x \in F(T) .
$$

In 2004, Xu [17] investigate Moudafi's viscosity method (1.1) in a Banach space $E$. He proved that the sequence defined by (1.1) converges strongly to a fixed point of $T$ and the fixed point also solves the following generalized variational inequality

$$
\langle(I-f) \widehat{x}, J(x-\widehat{x})\rangle \geq 0, \quad x \in F(T),
$$

where $J$ is the normal duality mapping provided that $E$ is uniformly smooth and $\left\{\alpha_{n}\right\}$ satisfies $C 1, C 2$ and $C 3$; see [17] and the references therein.

In 2008, Yao, Yao and Zhou [19] considered and analyzed a new viscosity iterative scheme for finding the common fixed point of a sequence of nonexpansive mappings in reflexive Banach spaces: $x_{1} \in C$ and

$$
x_{n+1}=\alpha_{n} f\left(x_{n}\right)+\beta x_{n}+\left(1-\alpha_{n}-\beta\right) W_{n} x_{n}, n \geq 1,
$$

where $\left\{\alpha_{n}\right\} \subset(0,1), \beta$ is a constant in $(0,1)$ and $W_{n}$ is the $W$-mapping which is defined by Shimoji and Takahashi [11]. They proved that $\left\{x_{n}\right\}$ converges strongly to a common fixed point $\hat{x}$ of the nonexpansive mappings and $\hat{x}$ is also the unique solution of variational inequality

$$
\langle(I-f) \widehat{x}, x-\widehat{x}\rangle \geq 0, \quad x \in F\left(W_{n}\right),
$$

provided that $\left\{\alpha_{n}\right\}$ satisfies $C 1$ and $C 2$.

Let $C$ be a nonempty subset of a real Banach space $X$. Let $\triangle$ denote the diagonal of the cartesian product $C \times C$. Consider a directed graph $G$ such that the set $V(G)$ of its vertices coincides with $C$, and the set $E(G)$ of its edge with $\triangle \subseteq E(G)$. We assume $G$ has no parallel edge. So we can identify the graph $G$ with the pair $(V(G), E(G))$. A mapping $T: C \rightarrow C$ is said to be

1. G-contraction if $T$ satisfies the conditions: 
(i) $T$ preserves edges of $G$, i.e.,

$$
(x, y) \in E(G) \Rightarrow(T x, T y) \in E(G), \forall(x, y) \in E(G)
$$

(ii) $T$ decreases weights of edges of $G$ in the following way: there exists $\alpha \in(0,1)$ such that

$$
(x, y) \in E(G) \Rightarrow\|T x-T y\| \leq \alpha\|x-y\|, \forall(x, y) \in E(G) ;
$$

2. G-nonexpansive if $T$ satisfies the conditions:

(i) $T$ preserves edges of $G$, i.e.,

$$
(x, y) \in E(G) \Rightarrow(T x, T y) \in E(G), \forall(x, y) \in E(G)
$$

(ii) $T$ non-increases weights of edges of $G$ in the following way:

$$
(x, y) \in E(G) \Rightarrow\|T x-T y\| \leq\|x-y\|, \forall(x, y) \in E(G) .
$$

In 2008, Jachymski [7] proved some generalizations of the Banach's contraction principle in complete metric spaces endowed with a graph. To be more precise, Jachymski proved the following result.

Theorem 1.1. [7] Let $(X, d)$ be a complete metric space. Assume that a triple $(X, d, G)$ has the following property: for any sequence $\left\{x_{n}\right\}$ if $x_{n} \rightarrow x$ and $\left(x_{n}, x_{n+1}\right) \in E(G)$ for $n \in \mathbb{N}$ and there is a subsequence $\left\{x_{n_{k}}\right\}$ of $\left\{x_{n}\right\}$ with $\left(x_{n_{k}}, x\right) \in E(G)$ for all $n \in \mathbb{N}$. Let $T: X \rightarrow X$ be a G-contraction, and $X_{T}=\{x \in X:$ $(x, T x) \in E(G)\}$. Then $F(T) \neq \emptyset$ if and only if $X_{T} \neq \emptyset$.

In 2015, Tiammee, Kaewkhao and Suantai [14] and Alfuraidan [1] employed the above theorem to establish the existence and convergence results for $G$-nonexpansive mappings with graphs.

Motivated by Takahashi and Takahashi [13] and Yao, Yao and Zhou [19], we prove strong convergence of two different viscosity approximation methods for $G$-nonexpansive mappings which was introduced by Tiammee, Kaewkhao and Suantai [14] in a Hilbert space. Furthermore, we also provide some numerical examples to support our main theorems.

\section{PRELIMINARIES}

Let $H$ be a real Hilbert space with inner product $\langle\cdot, \cdot\rangle$ and norm $\|\cdot\|$, respectively. Let $C$ be a nonempty closed convex subset of a real Hilbert space $H$. We write $x_{n} \rightarrow x$ to indicate that the sequence $\left\{x_{n}\right\}$ converges weakly to $x$ and $x_{n} \rightarrow x$ to indicate that $\left\{x_{n}\right\}$ converges strongly to $x$. Let $A: C \rightarrow H$ be a mapping. Recall that $A$ is said to be $\beta$-inverse-strongly-monotone if there exists a positive real number $\beta$ such that

$$
\langle A u-A v, u-v\rangle \geq \beta\|A u-A v\|^{2}, \forall u, v \in C .
$$

The classical variational inequality is to find $\widehat{x} \in C$ such that

$$
\langle A \widehat{x}, y-\widehat{x}\rangle \geq 0, \forall y \in C .
$$

The set of solutions of variational inequality (2.1) is denote by $\operatorname{VI}(C, A)$. For every point $x \in H$, there exists a unique nearest point in $C$, denoted by $P_{C} x$, such that

$$
\left\|x-P_{C} x\right\| \leq\|x-y\|
$$

for all $y \in C . P_{C}$ is called the metric projection of $H$ onto $C$. 
Lemma 2.1. [12] Let $C$ be a convex subset of a Hilbert space $H$ and let $x \in H$ and $y \in C$. Then the following are equivalent:

(i) $\|x-y\|=d(x, C)$;

(ii) $\langle x-y, y-z\rangle \geq 0$ for every $z \in C$.

Lemma 2.2. Let $H$ be a real Hilbert space. Then

$$
\|x+y\|^{2} \leq\|x\|^{2}+2\langle y, x+y\rangle, \quad \forall x, y \in H .
$$

Lemma 2.3. [18] Let $\left\{s_{n}\right\}$ be a sequence of non-negative real numbers satisfying

$$
s_{n+1} \leq\left(1-A_{n}\right) s_{n}+A_{n} B_{n}+C_{n}, \quad n \geq 0,
$$

where $\left\{A_{n}\right\},\left\{B_{n}\right\}$ and $\left\{C_{n}\right\}$ satisfy the conditions:

(i) $\left\{A_{n}\right\} \subset[0,1], \sum_{n=0}^{\infty} A_{n}=\infty$, or equivalently, $\prod_{n=1}^{\infty}\left(1-A_{n}\right)=0$;

(ii) $\limsup _{n \rightarrow \infty} B_{n} \leq 0$;

(iii) $C_{n} \geq 0$ for all $n \geq 0$ and $\sum_{n=0}^{\infty} C_{n}<\infty$.

Then $\lim _{n \rightarrow \infty} s_{n}=0$.

Lemma 2.4. [9] Let $\left\{x_{n}\right\}$ and $\left\{y_{n}\right\}$ be bounded sequences in a Banach space $X$ and let $\left\{\beta_{n}\right\}$ be a sequence in $[0,1]$ with $0<\liminf _{n \rightarrow \infty} \beta_{n} \leq \limsup _{n \rightarrow \infty} \beta_{n}<1$. Suppose $x_{n+1}=\beta_{n} y_{n}+\left(1-\beta_{n}\right) x_{n}$ for all integers $n \geq 1$ and $\lim \sup _{n}\left(\left\|y_{n+1}-y_{n}\right\|-\left\|x_{n+1}-x_{n}\right\|\right) \leq 0$. Then, $\lim _{n \rightarrow \infty}\left\|y_{n}-x_{n}\right\|=0$.

Lemma 2.5. [4] Let $H$ be a real Hilbert space and let $\left\{x_{i}\right\}_{i=1}^{m} \subseteq H$. For $\alpha_{i} \in(0,1), i=1,2, \ldots, m$ such that $\sum_{i=1}^{m} \alpha_{i}=1$, the following identity holds:

$$
\left\|\sum_{i=1}^{m} \alpha_{i} x_{i}\right\|^{2}=\sum_{i=1}^{m} \alpha_{i}\left\|x_{i}\right\|^{2}-\sum_{1 \leq i<j \leq m} \alpha_{i} \alpha_{j}\left\|x_{i}-x_{j}\right\|^{2} .
$$

Definition 2.1. Let $G=(V(G), E(G))$ be a directed graph. A graph $G$ is said to be transitive if for any $x, y, z \in V(G)$ such that $(x, y)$ and $(y, z)$ are in $E(G)$, then $(x, z) \in E(G)$.

Definition 2.2. Let $G=(V(G), E(G))$ be a directed graph. The set of edges $E(G)$ is said to be convex if for any $(x, y),(z, w) \in E(G)$ and for each $t \in(0,1)$, then $(t x+(1-t) z, t y+(1-t) w) \in E(G)$.

Lemma 2.6. Let $C$ be a nonempty closed convex subset of a Hilbert space $H$ and let $G=(V(G), E(G))$ be a directed graph such that $V(G)=C$. Let $T: C \rightarrow C$ be a G-nonexpansive mappings. Then

$$
\langle x-y,(I-T) x-(I-T) y\rangle \geq 0, \forall(x, y) \in E(G) .
$$

Proof. Let $(x, y) \in E(G)$. By the $G$-nonexpansiveness of $T$, we have

$$
\langle x-y,(I-T) x-(I-T) y\rangle=\|x-y\|^{2}-\langle x-y, T x-T y\rangle \geq 0 .
$$

Lemma 2.7. Let $C$ be a nonempty subset of a Banach space $X$ and $G=(V(G), E(G))$ a directed graph such that $V(G)=C$. Let $T: C \rightarrow C$ be a $G$-nonexpansive mapping. Then, for any $\varepsilon>0$, there exists $a$ positive number $\xi(\varepsilon)>0$ such that $\|x-T x\|<\varepsilon$ for all $x \in \operatorname{co}\left(\left\{x_{0}, x_{1}\right\}\right)$, whenever for $x_{0}, x_{1} \in C$ with $\left(x_{0}, x\right),\left(x_{1}, x\right) \in E(G),\left\|x_{0}-T x_{0}\right\| \leq \xi(\varepsilon)$ and $\left\|x_{1}-T x_{1}\right\| \leq \xi(\varepsilon)$. 
Proof. Let $x=(1-\lambda) x_{0}+\lambda x_{1}$, for some $\lambda \in[0,1]$ and $\varepsilon>0$.

We consider the following two cases.

Case I. If $\left\|x_{0}-x_{1}\right\|<\frac{\varepsilon}{3}$, then

$$
\left\|x-x_{0}\right\|=\lambda\left\|x_{0}-x_{1}\right\|<\frac{\varepsilon}{3}
$$

If $\xi(\varepsilon)<\frac{\varepsilon}{3}$, then

$$
\begin{aligned}
\|T x-x\| & \leq\left\|T x-T x_{0}\right\|+\left\|T x_{0}-x_{0}\right\|+\left\|x_{0}-x\right\| \\
& \leq 2\left\|x-x_{0}\right\|+\left\|T x_{0}-x_{0}\right\| \\
& <2\left(\frac{\varepsilon}{3}\right)+\xi(\varepsilon) \\
& <\varepsilon .
\end{aligned}
$$

Case II. If $\left\|x_{0}-x_{1}\right\| \geq \frac{\varepsilon}{3}$, then, for any nonnegative number $\lambda<\frac{\varepsilon}{3\left\|x_{0}-x_{1}\right\|}$,

$$
\left\|x-x_{0}\right\|=\lambda\left\|x_{0}-x_{1}\right\|<\frac{\varepsilon}{3}
$$

If $\xi(\varepsilon)<\frac{\varepsilon}{3}$ and $\lambda<\frac{\varepsilon}{3\left\|x_{0}-x_{1}\right\|}$, then

$$
\begin{aligned}
\|T x-x\| & \leq\left\|T x-T x_{0}\right\|+\left\|T x_{0}-x_{0}\right\|+\left\|x_{0}-x\right\| \\
& \leq 2\left\|x-x_{0}\right\|+\left\|T x_{0}-x_{0}\right\| \\
& <2\left(\frac{\varepsilon}{3}\right)+\xi(\varepsilon) \\
& <\varepsilon .
\end{aligned}
$$

We may assume that $\lambda \in\left[\frac{\varepsilon}{3\left\|x_{0}-x_{1}\right\|}, 1\right]$ and $\left\|x_{0}-x_{1}\right\| \geq \frac{\varepsilon}{3}$. It follows that

$$
\begin{aligned}
\left\|T x-x_{0}\right\| & \leq\left\|T x-T x_{0}\right\|+\left\|T x_{0}-x_{0}\right\| \\
& \leq\left\|x-x_{0}\right\|+\xi(\varepsilon) \\
& =\lambda\left\|x_{1}-x_{0}\right\|+\xi(\varepsilon)
\end{aligned}
$$

and

$$
\begin{aligned}
\left\|T x-x_{1}\right\| & \leq\left\|T x-T x_{1}\right\|+\left\|T x_{1}-x_{1}\right\| \\
& \leq\left\|x-x_{1}\right\|+\xi(\varepsilon) \\
& =(1-\lambda)\left\|x_{1}-x_{0}\right\|+\xi(\varepsilon) .
\end{aligned}
$$

From (2.2), (2.3) and $\lambda \in\left[\frac{\varepsilon}{3\left\|x_{0}-x_{1}\right\|}, 1\right]$, we get that

$$
\begin{aligned}
\|T x-x\| & \leq(1-\lambda)\left\|T x-x_{0}\right\|+\lambda\left\|T x-x_{1}\right\| \\
& \leq 2(1-\lambda) \lambda\left\|x_{1}-x_{0}\right\|+\xi(\varepsilon) \\
& <\varepsilon .
\end{aligned}
$$

We next prove the demiclosedness principle of $G$-nonexpansive mappings. 
Lemma 2.8. Let $C$ be a nonempty, closed and convex subset of a reflexive Banach space $X$ and $G=$ $(V(G), E(G))$ a directed graph such that $V(G)=C$. Let $T: C \rightarrow C$ be a $G$-nonexpansive mapping and $\left\{x_{n}\right\}$ be a sequence in $C$ such that $x_{n} \rightarrow x$ for some $x \in C$. If there exists a subsequence $\left\{x_{n_{k}}\right\}$ of $\left\{x_{n}\right\}$ such that $\left(x_{n_{k}}, x\right) \in E(G)$ for all $k \in \mathbb{N}$ and $\left\{x_{n}-T x_{n}\right\} \rightarrow y$ for some $y \in X$, then $(I-T) x=y$.

Proof. Let $\left\{x_{n}\right\}$ be a sequence in $C$ such that $x_{n} \rightarrow x$ and $\lim _{n \rightarrow \infty}\left\|x_{n}-T x_{n}-y\right\|=0$ for some $y \in X$. Set $T_{y} x=T x+y, x \in C$. Then $\left(I-T_{y}\right) x_{n}=(I-T) x_{n}-y$. We may assume, without loss of generality, that $y=0$. By the assumption, there exists a subsequence $\left\{x_{n_{k}}\right\}$ of $\left\{x_{n}\right\}$ such that $\left(x_{n_{k}}, x\right) \in E(G)$. We set $\varepsilon_{n_{k}}=\left\|x_{n_{k}}-T x_{n_{k}}\right\|$. Let $\varepsilon>0$. Since $\varepsilon_{n_{k}} \rightarrow 0$ as $k \rightarrow \infty$, there exists $N \in \mathbb{N}$ such that

$$
\varepsilon_{n_{k}}<\varepsilon, \forall k \geq N
$$

Lemma 2.7 gives that, for each $z \in \overline{c o}\left(\left\{x_{n_{k}}: k \geq N\right\}\right),\|z-T z\|<\varepsilon$. By the weak compactness of $\overline{c o}\left(\left\{x_{n_{k}}\right.\right.$ : $k \geq N\}$ ), it contains the weak limit $x$ of $\left\{x_{n_{k}}\right\}$. This shows that $\|x-T x\|<\varepsilon$. Hence $\|x-T x\|=0$, that is, $x=T x$, since $\varepsilon$ is arbitrary.

Proposition 2.1. Let $C$ be a convex subset of a vector space $X$. Let $G=(V(G), E(G))$ be a directed graph such that $V(G)=C$ and $E(G)$ is convex. Let $G$ be transitive and $f, T: C \rightarrow C$ be edge-preserving. Let $\left\{x_{n}\right\}$ be a sequence defined by (1.1) and $\left(x_{0}, f\left(x_{0}\right)\right)$ and $\left(x_{0}, T x_{0}\right)$ are in $E(G)$. If $\left\{x_{n}\right\}$ dominates $x_{0}$, then $\left(x_{n}, x_{n+1}\right),\left(x_{0}, x_{n}\right),\left(x_{n}, f\left(x_{n}\right)\right)$ and $\left(x_{n}, T x_{n}\right)$ are in $E(G)$ for any $n \in \mathbb{N}$.

Proof. We prove by induction. Since $E(G)$ is convex, $\left(x_{0}, f\left(x_{0}\right)\right)$ and $\left(x_{0}, T x_{0}\right)$ are in $E(G)$, we have $\left(x_{0}, x_{1}\right) \in E(G)$. Then $\left(f\left(x_{0}\right), f\left(x_{1}\right)\right)$ and $\left(T x_{0}, T x_{1}\right)$ are in $E(G)$, since $f$ and $T$ are edge-preserving. By assumption, $\left(x_{1}, x_{0}\right) \in E(G)$. Because $G$ is transitive, we have that $\left(x_{1}, f\left(x_{1}\right)\right)$ and $\left(x_{1}, T x_{1}\right)$ are in $E(G)$. So, by convexity of $E(G)$, we get $\left(x_{1}, x_{2}\right) \in E(G)$. Next, assume that $\left(x_{k}, x_{k+1}\right),\left(x_{0}, f\left(x_{k}\right)\right)$ and $\left(x_{0}, T x_{k}\right)$ are in $E(G)$. Then $\left(f\left(x_{k}\right), f\left(x_{k+1}\right)\right)$ and $\left(T x_{k}, T x_{k+1}\right)$ are in $E(G)$, since $f$ and $T$ are edge-preserving. From $\left\{x_{0}\right\}$ is dominated by $\left\{x_{n}\right\},\left(x_{k+1}, x_{0}\right) \in E(G)$. Since $G$ is transitive, we obtain that $\left(x_{k+1}, f\left(x_{k+1}\right)\right)$ and $\left(x_{k+1}, T x_{k+1}\right)$ are in $E(G)$. By convexity of $E(G)$, we get $\left(x_{k+1}, x_{k+2}\right) \in E(G)$. So, by induction, we can conclude that $\left(x_{n}, x_{n+1}\right),\left(x_{0}, x_{n}\right),\left(x_{n}, f\left(x_{n}\right)\right)$ and $\left(x_{n}, T x_{n}\right)$ are in $E(G)$ for any $n \in \mathbb{N}$.

\section{MAIN RESULTS}

In this section, we prove the existence theorem and prove strong convergence of viscosity approximation methods for $G$-nonexpansive mappings in a Hilbert space endowed with a graph.

Theorem 3.1. Let $C$ be a nonempty compact convex subset of a Hilbert space $H$ and let $G=(V(G), E(G))$ be a directed graph such that $V(G)=C$ and $E(G)$ is convex. Let $f: C \rightarrow C$ be a G-contraction mapping and let $T: C \rightarrow C$ be a $G$-nonexpansive mapping. Let $t_{n} \in(0,1)$ and $n \in \mathbb{N}$. Define $T_{t_{n}}: C \rightarrow C$ by

$$
T_{t_{n}} x=x_{n}=\left(1-t_{n}\right) f(x)+t_{n} T x, x \in C .
$$

Assume that, for every a subsequence $\left\{x_{n_{k}}\right\}$ of $\left\{x_{n}\right\}$, if $x_{n_{k}} \rightarrow z \in C$, then $\left(x_{n_{k}}, z\right),\left(x_{n_{k}}, x_{n_{k+1}}\right) \in E(G)$ for all $k \in \mathbb{N}$ and $(z, f(z)),(z, T z) \in E(G)$. Then the following hold:

(i) there exist $\hat{x}_{k} \in C$ such that $\hat{x}_{k}=T_{t_{n_{k}}} \hat{x}_{k}$ for all $k \in \mathbb{N}$;

(ii) if $t_{n} \rightarrow 1$ as $n \rightarrow \infty$, then $F(T) \neq \emptyset$;

(iii) if $F(T)$ is closed convex and $\left\{x_{n}\right\}$ dominates to $p$ for all $p \in F(T)$, there exists $\tilde{x} \in F(T)$ such that $\tilde{x}=P_{F(T)} f(\tilde{x})$, or equivalently, $\tilde{x}$ is the unique solution in $F(T)$ to the variational inequality

$$
\left\langle(I-f) \tilde{x}, x^{*}-\tilde{x}\right\rangle \geq 0, x^{*} \in F(T),
$$


where $P$ is the metric projection from $H$ onto $F(T)$.

Proof. (i) Let $x, y \in C$ such that $(x, y) \in E(G)$. It follows from $f$ and $T$ edge-preserving and the convexity of $E(G)$ that $\left(T_{t_{n}} x, T_{t_{n}} y\right) \in E(G)$ and

$$
\begin{aligned}
\left\|T_{t_{n}} x-T_{t_{n}} y\right\| & \leq\left(1-t_{n}\right)\|f(x)-f(y)\|+t_{n}\|T x-T y\| \\
& \leq\left(1-(1-\alpha)\left(1-t_{n}\right)\right)\|x-y\| .
\end{aligned}
$$

This implies that $T_{t_{n}}$ is $G$-contraction for all $n \in \mathbb{N}$. Since $C$ is compact, there exists a subsequence $\left\{T_{t_{n_{k}}} x\right\}$ of $\left\{T_{t_{n}} x\right\}$ such that $T_{t_{n_{k}}} \rightarrow z$ for some $z \in C$. It follows from the assumption and $E(G)$ is convex that

$$
\left(z, T_{t_{n_{k}}} z\right)=\left(z,\left(1-t_{n_{k}}\right) f(z)+t_{n_{k}} T z\right) \in E(G) .
$$

By the assumption again, we have $\left(x_{n_{k}}, z\right),\left(x_{n_{k}}, x_{n_{k+1}}\right) \in E(G)$ for all $k \in \mathbb{N}$. Applying Theorem 1.1, there exists $\hat{x}_{k} \in C$ such that $T_{t_{n_{k}}} \hat{x}_{k}=\hat{x}_{k}$.

(ii) Let $\hat{x}_{k}=\left(1-t_{n_{k}}\right) f\left(\hat{x}_{k}\right)+t_{n_{k}} T \hat{x}_{k}$. Since $C$ is bounded, one has

$$
\begin{aligned}
\left\|\hat{x}_{k}-T \hat{x}_{k}\right\| & \leq\left(1-t_{n_{k}}\right)\left\|f\left(\hat{x}_{k}\right)-T \hat{x}_{k}\right\| \\
& \leq\left(1-t_{n_{k}}\right) \operatorname{dim}(C) \rightarrow 0
\end{aligned}
$$

as $t_{n_{k}} \rightarrow 1$ as $k \rightarrow \infty$. Since $C$ is bounded, there exists a subsequence $\left\{\hat{x}_{k_{i}}\right\}$ of $\left\{\hat{x}_{k}\right\}$ such that $\hat{x}_{k_{i}} \rightarrow v \in C$ as $i \rightarrow \infty$. By the assumption, $\left(\hat{x}_{k_{i}}, v\right) \in E(G)$. It follows from Lemma 2.8 that $T v=v$. We thus complete the proof.

(iii) Since $\hat{x}_{k}=\left(1-t_{n_{k}}\right) f\left(\hat{x}_{k}\right)+t_{n_{k}} T \hat{x}_{k}$, we have

$$
(I-f) \hat{x}_{k}=\frac{-t_{n_{k}}}{1-t_{n_{k}}}(I-T) \hat{x}_{k} .
$$

Since $F(T)$ is closed, we may assume, without loss of generality, that $\hat{x}_{k} \rightarrow \tilde{x} \in F(T)$ as $k \rightarrow \infty$. Thus, for any $x^{*} \in F(T)$,

$$
\begin{aligned}
\left\langle(I-f) \hat{x}_{k}, \hat{x}_{k}-x^{*}\right\rangle & =-\frac{t_{n_{k}}}{1-t_{n_{k}}}\left\langle(I-T) \hat{x}_{k}, \hat{x}_{k}-x^{*}\right\rangle \\
& =-\frac{t_{n_{k}}}{1-t_{n_{k}}}\left\langle(I-T) \hat{x}_{k}-(I-T) x^{*}, \hat{x}_{k}-x^{*}\right\rangle \\
& \leq 0 .
\end{aligned}
$$

Taking the limit through $t_{n_{k}} \rightarrow 1$ as $k \rightarrow \infty$, one has

$$
\left\langle(I-f) \tilde{x}, \tilde{x}-x^{*}\right\rangle \leq 0 .
$$

Since $F(T)$ is closed and convex, we conclude that $\tilde{x}$ is unique. This completes the proof.

Theorem 3.2. Let $C$ be a nonempty closed convex subset of a Hilbert space $H$ and let $G=(V(G), E(G))$ be a directed graph such that $V(G)=C, E(G)$ is convex and $G$ is transitive. Let $f: C \rightarrow C$ be a $G$ contraction mapping and let $T: C \rightarrow C$ be a $G$-nonexpansive mapping such that $F(T) \neq \emptyset$. Let $\left\{\alpha_{n}\right\}$ be a sequence in $(0,1)$ with $C 1, C 2$ and $C 3$. Let $x_{0} \in C$ and $\left\{x_{n}\right\}$ be a sequence defined by

$$
x_{n+1}=\alpha_{n} f\left(x_{n}\right)+\left(1-\alpha_{n}\right) T x_{n}, \forall n \geq 0 .
$$

Assume that the following hold:

(i) $\left(x_{0}, f\left(x_{0}\right)\right)$ and $\left(x_{0}, T x_{0}\right)$ are in $E(G)$; 
(ii) $F(T)$ is closed and $F(T) \times F(T) \subseteq E(G)$;

(iii) $\left\{x_{n}\right\}$ dominates $x_{0}$ and $p$ for all $p \in F(T)$;

(iv) for every a subsequence $\left\{x_{n_{k}}\right\}$ of $\left\{x_{n}\right\}$, if $x_{n_{k}} \rightarrow x \in C$, then $\left(x_{n_{k}}, x\right) \in E(G)$ for all $k \in \mathbb{N}$.

Then $\left\{x_{n}\right\}$ converges strongly to $z=P f(z)$ and it is the unique solution of variational inequality

$$
\langle(I-f) z, p-z\rangle \geq 0, p \in F(T),
$$

where $P$ is the metric projection on $F(T)$.

Proof. We first show that $\left\{x_{n}\right\}$ is bounded. Let $p \in F(T)$. By (iii), we have $\left(x_{n}, p\right) \in E(G)$ and

$$
\begin{aligned}
\left\|x_{n+1}-p\right\| & =\left\|\alpha_{n} f\left(x_{n}\right)+\left(1-\alpha_{n}\right) T x_{n}-p\right\| \\
& \leq \alpha_{n}\left(\left\|f\left(x_{n}\right)-f(p)\right\|+\|f(p)-p\|\right)+\left(1-\alpha_{n}\right)\left\|x_{n}-p\right\| \\
& \leq \alpha_{n}\left(\alpha\left\|x_{n}-p\right\|+\|f(p)-p\|\right)+\left(1-\alpha_{n}\right)\left\|x_{n}-p\right\| \\
& =\left(1-\alpha_{n}(1-\alpha)\right)\left\|x_{n}-p\right\|+\alpha_{n}(1-\alpha) \frac{1}{1-\alpha}\|f(p)-p\| \\
& \leq \max \left\{\left\|x_{0}-p\right\|, \frac{1}{1-\alpha}\|f(z)-p\|\right\} .
\end{aligned}
$$

Hence $\left\{x_{n}\right\}$ is bounded. We also obtain that $\left\{T x_{n}\right\}$ and $\left\{f\left(x_{n}\right)\right\}$ are bounded. By Proposition 2.1, we have

$$
\begin{aligned}
\left\|x_{n+1}-x_{n}\right\|= & \left\|\alpha_{n} f\left(x_{n}\right)+\left(1-\alpha_{n}\right) T x_{n}-\alpha_{n-1} f\left(x_{n-1}\right)-\left(1-\alpha_{n-1}\right) T x_{n-1}\right\| \\
= & \| \alpha_{n} f\left(x_{n}\right)-\alpha_{n} f\left(x_{n-1}\right)+\alpha_{n} f\left(x_{n-1}\right)-\alpha_{n-1} f\left(x_{n-1}\right) \\
& +\left(1-\alpha_{n}\right) T x_{n}-\left(1-\alpha_{n}\right) T x_{n-1}+\left(1-\alpha_{n}\right) T x_{n-1}-\left(1-\alpha_{n-1}\right) T x_{n-1} \| \\
\leq & \left(1-\alpha_{n}(1-\alpha)\right)\left\|x_{n}-x_{n-1}\right\|+2 K\left|\alpha_{n}-\alpha_{n-1}\right|,
\end{aligned}
$$

where

$$
K=\sup \left\{\left\|f\left(x_{n}\right)\right\|+\left\|T x_{n}\right\|: n \in \mathbb{N}\right\}
$$

By Lemma 2.3, we get

$$
\lim _{n \rightarrow \infty}\left\|x_{n+1}-x_{n}\right\|=0
$$

Using (1.1), we have

$$
\begin{aligned}
\left\|x_{n}-T x_{n}\right\| & \leq\left\|x_{n}-x_{n+1}\right\|+\left\|x_{n+1}-T x_{n}\right\| \\
& =\left\|x_{n}-x_{n+1}\right\|+\alpha_{n}\left\|f\left(x_{n}\right)-T x_{n}\right\| .
\end{aligned}
$$

From $C 1$ and (3.2), we obtain

$$
\lim _{n \rightarrow \infty}\left\|x_{n}-T x_{n}\right\|=0
$$

Next, we show that

$$
\limsup _{n \rightarrow \infty}\left\langle f(z)-z, x_{n}-z\right\rangle \leq 0
$$

We know that $F(T)$ is convex provided that $F(T) \times F(T) \subseteq E(G)$; see [14, Theorem 3.2]. By the assumption (ii), we obtain that $F(T)$ is closed and convex. Hence, $z=P f(z)$ is well-defined. Take a subsequence $\left\{x_{n_{k}}\right\}$ of $\left\{x_{n}\right\}$ such that

$$
\limsup _{n \rightarrow \infty}\left\langle f(z)-z, x_{n}-z\right\rangle=\lim _{k \rightarrow \infty}\left\langle f(z)-z, x_{n_{k}}-z\right\rangle .
$$


Because all the $x_{n_{k}}$ lie in the weakly compact set $C$ and the assumption (iv), we may assume, without loss of generality, that $x_{n_{k}} \rightarrow y$ for some $y \in C$ and $\left(x_{n_{k}}, y\right) \in E(G)$. It follows from Lemma 2.8 and (3.3) that $y=T y$. Thus, by Theorem 3.1 (iii), we obtain

$$
\lim _{k \rightarrow \infty}\left\langle f(z)-z, x_{n_{k}}-z\right\rangle=\langle f(z)-z, y-z\rangle \leq 0 .
$$

Hence

$$
\limsup _{n \rightarrow \infty}\left\langle f(z)-z, x_{n}-z\right\rangle \leq 0 .
$$

By Lemma 2.2, $G$-contractioness of $f$ and the $G$-nonexpansiveness of $T$, we get

$$
\begin{aligned}
\left\|x_{n+1}-z\right\|^{2} & \leq\left(1-\alpha_{n}\right)^{2}\left\|T x_{n}-z\right\|^{2}+2 \alpha_{n}\left\langle f\left(x_{n}\right)-z, x_{n+1}-z\right\rangle \\
& \leq\left(1-\alpha_{n}\right)^{2}\left\|x_{n}-z\right\|^{2}+2 \alpha_{n}\left\langle f\left(x_{n}\right)-f(z), x_{n+1}-z\right\rangle+2 \alpha_{n}\left\langle f(z)-z, x_{n+1}-z\right\rangle \\
& \leq\left(1-\alpha_{n}\right)^{2}\left\|x_{n}-z\right\|^{2}+2 \alpha_{n} \alpha\left\|x_{n}-z\right\|\left\|x_{n+1}-z\right\|+2 \alpha_{n}\left\langle f(z)-z, x_{n+1}-z\right\rangle \\
& \leq\left(1-\alpha_{n}\right)^{2}\left\|x_{n}-z\right\|^{2}+\alpha_{n} \alpha\left\{\left\|x_{n}-z\right\|^{2}+\left\|x_{n+1}-z\right\|^{2}\right\}+2 \alpha_{n}\left\langle f(z)-z, x_{n+1}-z\right\rangle .
\end{aligned}
$$

This implies that

$$
\begin{aligned}
\left\|x_{n+1}-z\right\|^{2} \leq & \frac{1-2 \alpha_{n}+\alpha_{n} \alpha}{1-\alpha_{n} \alpha}\left\|x_{n}-z\right\|^{2}+\frac{\alpha_{n}^{2}}{1-\alpha_{n} \alpha}\left\|x_{n}-z\right\|^{2}+\frac{2 \alpha_{n}}{1-\alpha_{n} \alpha}\left\langle f(z)-z, x_{n+1}-z\right\rangle \\
\leq & \left(1-\frac{2(1-\alpha) \alpha_{n}}{1-\alpha_{n} \alpha}\right)\left\|x_{n}-z\right\|^{2} \\
& +\frac{2(1-\alpha) \alpha_{n}}{1-\alpha_{n} \alpha}\left\{\frac{\alpha_{n}}{2(1-\alpha)}\left\|x_{n}-z\right\|^{2}+\frac{1}{1-\alpha}\left\langle f(z)-z, x_{n+1}-z\right\rangle\right\} .
\end{aligned}
$$

Put $A_{n}=\frac{2(1-\alpha) \alpha_{n}}{1-\alpha \alpha_{n}}$ and

$$
B_{n}=\frac{\alpha_{n}}{2(1-\alpha)}\left\|x_{n}-z\right\|^{2}+\frac{1}{1-\alpha}\left\langle f(z)-z, x_{n+1}-z\right\rangle .
$$

It follows from $C 1$ and (3.4) that $\sum_{n=0}^{\infty} A_{n}=\infty$ and $\limsup _{n \rightarrow \infty} B_{n} \leq 0$. By Lemma 2.3, we can conclude that

$$
\lim _{n \rightarrow \infty}\left\|x_{n}-z\right\|^{2}=0
$$

Therefore $\left\{x_{n}\right\}$ converges strongly to $z=P f(z)$.

Remark 3.1. Theorem 3.2 extends the main result of $\mathrm{Xu}$ [17] from a nonexpansive mapping to a $G$ nonexpansive mapping.

Theorem 3.3. Let $C$ be a nonempty closed convex subset of a Hilbert space $H$ and let $G=(V(G), E(G))$ be a directed graph such that $V(G)=C, E(G)$ is convex and $G$ is transitive. Let $f: C \rightarrow C$ be a $G$ contraction mapping and let $T: C \rightarrow C$ be a G-nonexpansive mapping such that $F(T) \neq \emptyset$. Let $\left\{\alpha_{n}\right\}$, $\left\{\beta_{n}\right\}$ and $\left\{\gamma_{n}\right\}$ be sequences in $(0,1)$. Let $x_{0} \in C$ and $\left\{x_{n}\right\}$ be a sequence defined by

$$
x_{n+1}=\alpha_{n} f\left(x_{n}\right)+\beta_{n} x_{n}+\gamma_{n} T x_{n}, \forall n \geq 0 .
$$

Assume that the following hold:

(i) there exists $x_{0} \in C$ such that $\left(x_{0}, f\left(x_{0}\right)\right)$ and $\left(x_{0}, T x_{0}\right)$ are in $E(G)$;

(ii) $F(T)$ is closed and $F(T) \times F(T) \subseteq E(G)$;

(iii) $\left\{x_{n}\right\}$ dominates $x_{0}$ and $p$ for all $p \in F(T)$; 
(iv) for every a subsequence $\left\{x_{n_{k}}\right\}$ of $\left\{x_{n}\right\}$, if $x_{n_{k}} \rightarrow x \in C$, then $\left(x_{n_{k}}, x\right) \in E(G)$ for all $k \in \mathbb{N}$;

(v) $\left\{\alpha_{n}\right\}$ satisfies $C 1$ and $C 2$;

(vi) $\limsup _{n \rightarrow \infty} \beta_{n}<1$ and $\liminf _{n \rightarrow \infty} \beta_{n} \gamma_{n}>0$.

Then $\left\{x_{n}\right\}$ converges strongly to $z=P f(z)$ and it is the unique solution of variational inequality

$$
\langle(I-f) z, p-z\rangle \geq 0, p \in F(T),
$$

where $P$ is the metric projection on $F(T)$.

Proof. Let $p \in F(T)$. By (iii), we have $\left(x_{n}, p\right) \in E(G)$ and

$$
\begin{aligned}
\left\|x_{n+1}-p\right\| & =\left\|\alpha_{n} f\left(x_{n}\right)+\beta_{n} x_{n}+\gamma_{n} T x_{n}-p\right\| \\
& \leq \alpha_{n}\left(\left\|f\left(x_{n}\right)-f(p)\right\|+\|f(p)-p\|\right)+\left(\beta_{n}+\gamma_{n}\right)\left\|x_{n}-p\right\| \\
& \leq \alpha_{n}\left(\alpha\left\|x_{n}-p\right\|+\|f(p)-p\|\right)+\left(\beta_{n}+\gamma_{n}\right)\left\|x_{n}-p\right\| \\
& =\left(1-\alpha_{n}(1-\alpha)\right)\left\|x_{n}-p\right\|+\alpha_{n}(1-\alpha) \frac{1}{1-\alpha}\|f(p)-p\| \\
& \leq \max \left\{\left\|x_{0}-p\right\|, \frac{1}{1-\alpha}\|f(z)-p\|\right\} .
\end{aligned}
$$

Hence $\left\{x_{n}\right\}$ is bounded. Consequently, we deduce that $\left\{T x_{n}\right\}$ and $\left\{f\left(x_{n}\right)\right\}$ are bounded. Setting

$$
x_{n+1}=\beta_{n} x_{n}+\left(1-\beta_{n}\right) s_{n},
$$

one implies from (3.5) that

Further, it follows that

$$
s_{n}=\frac{x_{n+1}-\beta_{n} x_{n}}{1-\beta_{n}}=\frac{\alpha_{n} f\left(x_{n}\right)+\gamma_{n} T x_{n}}{1-\beta_{n}} .
$$

$$
\begin{aligned}
s_{n+1}-s_{n} & =\frac{\alpha_{n+1} f\left(x_{n+1}\right)+\gamma_{n+1} T x_{n+1}}{1-\beta_{n+1}}-\frac{\alpha_{n} f\left(x_{n}\right)+\gamma_{n} T x_{n}}{1-\beta_{n}} \\
& =\frac{\alpha_{n}}{1-\beta_{n}}\left(T x_{n}-f\left(x_{n}\right)\right)+\frac{\alpha_{n+1}}{1-\beta_{n+1}}\left(f\left(x_{n+1}\right)-T x_{n}\right)+\frac{\gamma_{n+1}}{1-\beta_{n+1}}\left(T x_{n+1}-T x_{n}\right) .
\end{aligned}
$$

It follows from Proposition 2.1 that

$$
\begin{aligned}
\left\|s_{n+1}-s_{n}\right\|-\left\|x_{n+1}-x_{n}\right\| \leq & \frac{\alpha_{n}}{1-\beta_{n}}\left(\left\|T x_{n}\right\|+\left\|f\left(x_{n}\right)\right\|\right)+\frac{\alpha_{n+1}}{1-\beta_{n+1}}\left(\left\|f\left(x_{n+1}\right)\right\|+\left\|T x_{n}\right\|\right) \\
& +\left(\frac{\gamma_{n+1}}{1-\beta_{n+1}}-1\right)\left\|x_{n+1}-x_{n}\right\| .
\end{aligned}
$$

By the assumption (v) and (vi), we obtain

$$
\limsup _{n \rightarrow \infty}\left\{\left\|s_{n+1}-s_{n}\right\|-\left\|x_{n+1}-x_{n}\right\|\right\} \leq 0 .
$$

Hence, by Lemma 2.4, we have

$$
\lim _{n \rightarrow \infty}\left\|s_{n}-x_{n}\right\|=0
$$

Now, we have

$$
\begin{aligned}
\left\|x_{n+1}-x_{n}\right\| & =\left\|\beta_{n} x_{n}+\left(1-\beta_{n}\right) s_{n}-x_{n}\right\| \\
& =\left(1-\beta_{n}\right)\left\|s_{n}-x_{n}\right\| .
\end{aligned}
$$

It follows from (3.6) that

$$
\lim _{n \rightarrow \infty}\left\|x_{n+1}-x_{n}\right\|=0 .
$$


By (iii), we know that $\left(x_{n}, p\right) \in E(G)$ for all $p \in F(T)$. It follows from Lemma 2.5 that

$$
\begin{aligned}
\left\|x_{n+1}-p\right\|^{2} & =\left\|\alpha_{n} f\left(x_{n}\right)+\beta_{n} x_{n}+\gamma_{n} T x_{n}-p\right\|^{2} \\
& \leq \alpha_{n}\left\|f\left(x_{n}\right)-p\right\|^{2}+\beta_{n}\left\|x_{n}-p\right\|^{2}+\gamma_{n}\left\|T x_{n}-p\right\|^{2}-\beta_{n} \gamma_{n}\left\|x_{n}-T x_{n}\right\|^{2} \\
& \leq \alpha_{n}\left\|f\left(x_{n}\right)-p\right\|^{2}+\left(1-\alpha_{n}\right)\left\|x_{n}-p\right\|^{2}-\beta_{n} \gamma_{n}\left\|x_{n}-T x_{n}\right\|^{2} .
\end{aligned}
$$

This implies that

$$
\beta_{n} \gamma_{n}\left\|x_{n}-T x_{n}\right\|^{2} \leq \alpha_{n}\left\|f\left(x_{n}\right)-p\right\|^{2}+\left\|x_{n}-p\right\|^{2}-\left\|x_{n+1}-p\right\|^{2} .
$$

It follows from (v), (vi), (3.7) and (3.8) that

$$
\lim _{n \rightarrow \infty}\left\|x_{n}-T x_{n}\right\|=0 .
$$

By the same proof in Theorem 3.2, we get

$$
\limsup _{n \rightarrow \infty}\left\langle f(z)-z, x_{n}-z\right\rangle \leq 0 .
$$

By Lemma 2.2, $G$-contractioness of $f$ and the $G$-nonexpansiveness of $T$, we get

$$
\begin{aligned}
\left\|x_{n+1}-z\right\|^{2} \leq & \left\|\beta_{n}\left(x_{n}-z\right)+\gamma_{n}\left(T x_{n}-z\right)\right\|^{2}+2 \alpha_{n}\left\langle f\left(x_{n}\right)-z, x_{n+1}-z\right\rangle \\
\leq & \left(\beta_{n}\left\|x_{n}-z\right\|+\gamma_{n}\left\|T x_{n}-z\right\|\right)^{2}+2 \alpha \alpha_{n}\left\|x_{n}-z\right\|\left\|x_{n+1}-z\right\| \\
& +2 \alpha_{n}\left\langle f(z)-z, x_{n+1}-z\right\rangle \\
\leq & \left(1-\alpha_{n}\right)^{2}\left\|x_{n}-z\right\|^{2}+\alpha \alpha_{n}\left(\left\|x_{n}-z\right\|^{2}+\left\|x_{n+1}-z\right\|\right) \\
& +2 \alpha_{n}\left\langle f(z)-z, x_{n+1}-z\right\rangle \\
= & \left(1-\frac{2(1-\alpha) \alpha_{n}}{1-\alpha_{n} \alpha}\right)\left\|x_{n}-z\right\|^{2} \\
& +\frac{2(1-\alpha) \alpha_{n}}{1-\alpha_{n} \alpha}\left(\frac{\alpha_{n}}{2(1-\alpha)}\left\|x_{n}-z\right\|^{2}+\frac{1}{1-\alpha}\left\langle f(z)-z, x_{n+1}-z\right\rangle\right) .
\end{aligned}
$$

Put $A_{n}=\frac{2(1-\alpha) \alpha_{n}}{1-\alpha_{n} \alpha}$ and

$$
B_{n}=\frac{\alpha_{n}}{2(1-\alpha)}\left\|x_{n}-z\right\|^{2}+\frac{1}{1-\alpha}\left\langle f(z)-z, x_{n+1}-z\right\rangle .
$$

It follows from (v) and (3.10) that $\sum_{n=0}^{\infty} A_{n}=\infty$ and $\limsup _{n \rightarrow \infty} B_{n} \leq 0$. By Lemma 2.3, we obtain that

$$
\lim _{n \rightarrow \infty}\left\|x_{n}-z\right\|^{2}=0
$$

Therefore $\left\{x_{n}\right\}$ converges strongly to $z=P f(z)$.

If $T$ is a nonexpansive mapping, then we obtain the following corollary immediately.

Corollary 3.1. Let $C$ be a nonempty closed convex subset of a Hilbert space $H$. Let $f: C \rightarrow C$ be a contraction mapping and let $T: C \rightarrow C$ be a nonexpansive mapping such that $F(T) \neq \emptyset$. Let $\left\{\alpha_{n}\right\},\left\{\beta_{n}\right\}$ and $\left\{\gamma_{n}\right\}$ be sequences in $(0,1)$. Let $x_{0} \in C$ and $\left\{x_{n}\right\}$ be a sequence defined by

$$
x_{n+1}=\alpha_{n} f\left(x_{n}\right)+\beta_{n} x_{n}+\gamma_{n} T x_{n}, \forall n \geq 0 .
$$

Assume that the following hold:

(i) $\left\{\alpha_{n}\right\}$ satisfies $C 1$ and $C 2$; 
(ii) $\limsup _{n \rightarrow \infty} \beta_{n}<1$ and $\liminf _{n \rightarrow \infty} \beta_{n} \gamma_{n}>0$.

Then $\left\{x_{n}\right\}$ converges strongly to $z=P f(z)$ and it is the unique solution of variational inequality

$$
\langle(I-f) z, p-z\rangle \geq 0, p \in F(T),
$$

where $P$ is the metric projection on $F(T)$.

\section{NUMERICAL EXAMPLES}

In this section, we give examples and numerical results for supporting our main theorem.

Example 4.1. Let $H=\mathbb{R}$ and $C=(0,2]$. Suppose that $\left\{x_{n}\right\}$ generated by (3.1). Assume that $(x, y) \in$ $E(G)$ if and only if $\frac{7}{10} \leq x, y \leq 2$ or $x=y$. Define two mappings $f, T: C \rightarrow C$ by

$$
f(x)=\frac{x^{2}+2}{4 x} \text { and } T x=e^{\frac{2}{3}(1-x)}
$$

for any $x \in C$. It is easy to check that $f$ is $G$-contraction and $T$ is G-nonexpansive. On the other hand, $f$ is not contraction and $T$ is not nonexpansive since for $x=\frac{7}{10}$ and $y=\frac{1}{10}$. This implies that

$$
|f(x)-f(y)|>\frac{3}{5}>a|x-y|,
$$

for all $a \in(0,1)$ and

$$
|T x-T y|>\frac{3}{5}=|x-y| \text {. }
$$

Let $\alpha_{n}=\frac{1}{10 n+3}$. We know that $\left\{\alpha_{n}\right\}$ satisfies $C 1, C 2$ and $C 3$. Choose $x_{0}=\frac{3}{2}$. By computing, we obtain the sequence $\left\{x_{n}\right\}$ generated by (3.1) converges to 1 . Then we show the error plotting $\left\|x_{n+1}-x_{n}\right\|$.

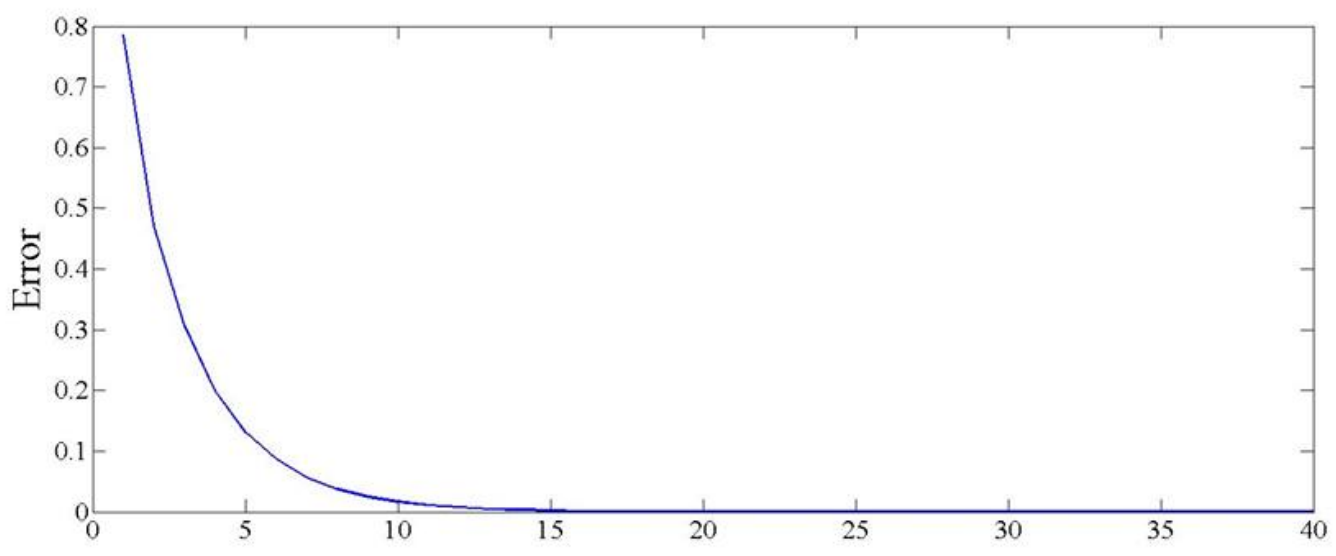

Figure 1. Error plots of $\left\|x_{n+1}-x_{n}\right\|$.

Example 4.2. Let $H=\mathbb{R}$ and $C=(0,2]$. Suppose that $\left\{x_{n}\right\}$ generated by (3.5). Assume that $(x, y) \in$ $E(G)$ if and only if $\frac{7}{10} \leq x, y \leq 2$ or $x=y$. Define two mappings $f, T: C \rightarrow C$ by

$$
f(x)=\frac{x^{2}+2}{4 x} \text { and } T x=e^{\frac{2}{3}(1-x)}
$$

for any $x \in C$. By Example 4.1, we know that $f$ is $G$-contraction and $T$ is $G$-nonexpansive. Let

$$
\alpha_{n}= \begin{cases}\frac{1}{100(\sqrt{n+1}-1)}, & \text { if } n \text { is odd } \\ \frac{1}{100 \sqrt{n+1}}, & \text { if } n \text { is even }\end{cases}
$$


We know that $\left\{\alpha_{n}\right\}$ satisfies $C 1$ and $C 2$ but not $C 3$. Let

$$
\beta_{n}= \begin{cases}\frac{98 \sqrt{n+1}-99}{100(\sqrt{n+1}-1)}, & \text { if } n \text { is odd } \\ \frac{49}{50}, & \text { if } n \text { is even }\end{cases}
$$

and

$$
\alpha_{n}= \begin{cases}\frac{1}{50}, & \text { if } n \text { is odd; } \\ \frac{2 \sqrt{n+1}-1}{100 \sqrt{n+1}}, & \text { if } n \text { is even. }\end{cases}
$$

Choose $x_{0}=\frac{3}{2}$. By computing, we obtain the sequence $\left\{x_{n}\right\}$ generated by (3.5) converges to 1 . Then we show the error plotting $\left\|x_{n+1}-x_{n}\right\|$.

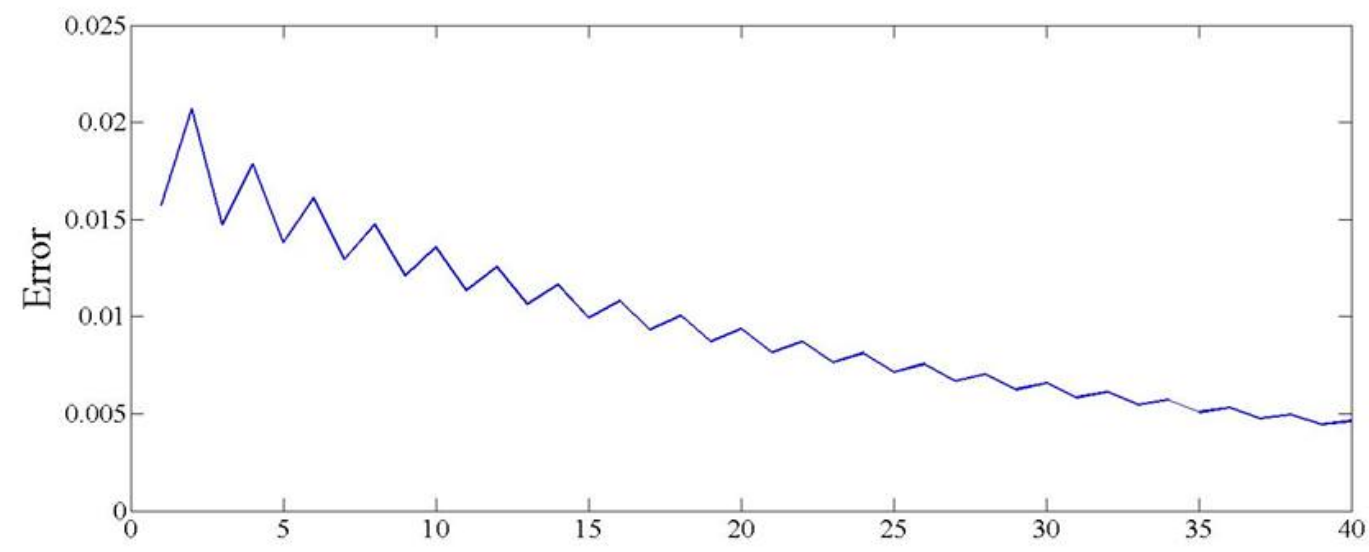

Figure 2. Error plots of $\left\|x_{n+1}-x_{n}\right\|$.

\section{Acknowledgments}

The authors would like to thank the referees for valuable comments and suggestions for improving this paper. The first author would like to thank the Thailand Research Fund under the Project MRG6080105.

\section{REFERENCES}

[1] M.R. Alfuraidan, Fixed points of monotone nonexpansive mappings with a graph, Fixed Point Theory Appl. 2015 (2015), Article ID 49.

[2] S. Banach, Sur les oprations dans les ensembles abstraits et leur application aux quations intgrales, Fund. Math. 3 (1922), 133-181.

[3] F.E. Browder, Convergence of approximants to fixed points of non-expansive maps in Banach spaces, Arch. Rational Mech. Anal. 24 (1967), 82-90.

[4] C.E. Chidume, J.N. Ezeora, Krasnoselkii-type algorithm for family of multi-valued strictly pseudo-contractive mappings, Fixed Point Theory Appl. 2014 (2014), Article ID 111.

[5] B. Halpern, Fixed points of nonexpanding maps, Bull. Amer. Math. Soc. 73 (1967), 957-961.

[6] D. Gohde, Zum Prinzip def kontraktiven Abbildung, Math. Nachr. 30 (1965), 251-258.

[7] J. Jachymski, The contraction principle for mappings on a metric space with a graph, Proc. Amer. Math. Soc. 136 (2008), 1359-1373.

[8] W. Kirm, Kirk, A fixed point theorem for mappings which do not increase distances, Amer. Math. Monthly 72 (1965), 1004-1006.

[9] T. Suzuki, Strong convergence theorems for infinite families of nonexpansive mappings in general Banach spaces, Fixed Point Theory Appl. 2005 (2005), Article ID 685918.

[10] A. Moudafi, Viscosity approximation methods for fixed-points problems, J. Math. Anal. Appl. 241 (2000), 46-55. 
[11] K. Shimoji, W. Takahashi, Strong convergence to common fixed points of infinite nonexpasnsive mappings and applications, Taiwanese J. Math. 5 (2001) 387-404.

[12] W. Takahashi, Nonlinear Functional Analysis, Yokohama Publishers, Yokohama, (2000).

[13] S. Takahashi, W. Takahashi, Viscosity approximation methods for equilibrium problems and fixed point problems in Hilbert spaces, J. Math. Anal. Appl. 331 (2007), 506-515.

[14] J. Tiammee, A. Kaewkhao, S. Suantai, On Browder's convergence theorem and Halpern iteration process for Gnonexpansive mappings in Hilbert spaces endowed with graphs, Fixed Point Theory Appl. 2015 (2015), Article ID 187.

[15] R. Wittmann, Approximation of fixed points of nonexpansive mappings, Arch. Math. (Basel). 58 (1992), $486-491$.

[16] H.K. Xu. G. Marino, A general iterative method for nonexpansive mappings in Hilbert spaces, J. Math. Anal. Appl. 318 (2006), 43-52.

[17] H.K. Xu, Viscosity approximation methods for nonexpansive mappings, J. Math. Anal. Appl. 298 (2004), $279-291$.

[18] H.K. Xu, Iterative algorithms for nonlinear operators, J. London Math. Soc. 66 (2002), 240-256.

[19] Y. Yao, J.C. Yao, H.Y. Zhou, Approximation methods for common fixed points of infinite countable family of nonexpansive mappings, Comput. Math. Appl. 53 (2007) 1380-1389. 